\title{
Effects of Doping Elements on the Friction and Wear of SUJ2 Steel Sliding against Aluminum Alloys
}

\author{
Yuh-Ping Chang *, Zi-Wei Huang and Huann-Ming Chou \\ Department of Mechanical Engineering, Kun Shan University, Tainan 710, Taiwan; \\ g0910799199@gmail.com (Z.-W.H.); hmchou@mail.ksu.edu.tw (H.-M.C.) \\ * Correspondence: ypc0318@mail.ksu.edu.tw; Tel.: +886-6-272-7175
}

Academic Editor: Jeng-Haur Horng

Received: 7 February 2017; Accepted: 17 March 2017; Published: 23 March 2017

\begin{abstract}
Damage to mechanical components caused by wear is considered to be an important issue for mechanical engineers. For the purpose of wear resistance, it is necessary to improve the material properties of the mechanical elements. Furthermore, low friction plays an important role in saving energy. Hence, it is important to establish a key technology for wear resistance and low friction through appropriate materials science for related industries. In general, the tribological properties of aluminum alloys are very different from those of steels. Hence, aluminum alloys should be specially considered and clarified for their tribological properties before being applied industrially. This paper therefore aims to further investigate the effects of the content of doping elements on the friction and wear of the selected aluminum alloys. From the experimental results, it can be concluded that the higher the Si content, the smaller the friction coefficient, and the milder the variation. The higher the content of iron and copper, the more materials are removed, showing better machinability. Moreover, three frictional models and wear mechanisms that describe the effects of the content of doping elements on the friction and wear are proposed. The wear mechanisms change as the silicon content increases, from the junction growth to the wedge and the ploughing particles. As a result, better choices of aluminum alloys with regards to friction and wear can then be made. These results have great practical importance.
\end{abstract}

Keywords: aluminum alloy; silicon; friction; wear

\section{Introduction}

With the rapid developments of traffic vehicles and key transmission components, the demand for safe and lightweight new materials is growing, and with the global demand for energy saving and carbon reduction, the industry urgently needs to develop lightweight, reliable and environmentally friendly materials. Of the metal contained in the earth, aluminum is the second most abundant, behind iron. Hence, aluminum and its chemical compositions are the materials with large development potential [1-4]. In addition, due to its light weight, high strength, acceptable corrosion resistance and good machinability, aluminum alloy is widely used in aerospace machinery [5], defense and people's livelihood industry. The early aluminum alloy material aimed at being lightweight, and did not consider the enhancement of wear resistance, therefore, although aluminum alloy had high strength and durability, its abrasion resistance was always significantly worse than that of steel [6]. In order to apply aluminum alloy to advanced transport vehicles and key transmission parts, further improvement of the wear properties of aluminum alloy materials is the main project of product development.

Since silicon is a very strong element, if its particles are added to the industrial material, the abrasion resistance of the material can be greatly enhanced, and therefore its applicability is greatly increased [7]. Sarkar and Prasad [8,9] found that the crystal structures of silicon will affect the wear properties of aluminum alloys. If they are further mixed with an appropriate amount of $\mathrm{Ni}, \mathrm{Cu}$ and 
$\mathrm{Mg}$, their mechanical properties can then be improved. Over recent decades, these research topics have been continuously investigated by national scholars [10-16].

Some researchers have found that certain elements may degrade wear properties such as $\mathrm{Fe}$ or Mn. It is generally believed that this is because Fe and Mn react with silicon to produce some special compounds, which reduce the effective volume of the silicon particles and reduce the wear properties [17]. Wear behavior refers to the gradual removal of solid surface material by mechanical actions; if the wear rate is lower, a longer experimental time is required to identify the difference [18]. Moreover, Alpas, Hu, and Zhang [19-21], Li and Tandon [22], and Subramanian [23] designed dry wear tests for various aluminum alloys to speed up the experiments and obtain clearer results. Wang [24,25] clarified the relations between the frictional temperature, wear, microstructures, normal loads and sliding speeds of the steel 52100. The studies of Moghadam [26-28] revealed that the addition of suitable elements to metals decreases both the friction coefficients and wear rate as well as increasing the tensile strength. Moreover, the composites have good tribological properties under limited lubricated conditions due to graphite particles acting as a solid lubricant on worn surfaces.

Based on the above documents, five aluminum alloys which are frequently used in industrial circles are used in this study for friction and wear experiments, in order to analyze and compare the effects of doping elements on the friction and wear of SUJ2 steel sliding against the aluminum alloys under the selected experimental conditions.

\section{Experimental Apparatus and Procedures}

Figure 1 shows a schematic diagram of the ball/disk friction tester and the measurement system. The friction coefficient is dynamically measured and exported by variations of electrical voltage through the load cell. The electronic signals are captured by a data acquisition system, and these data are processed and analyzed by a personal computer. Wear loss is measured and quantitatively analyzed by a microbalance, and microscopic wear particles are qualitatively observed by the SEM.

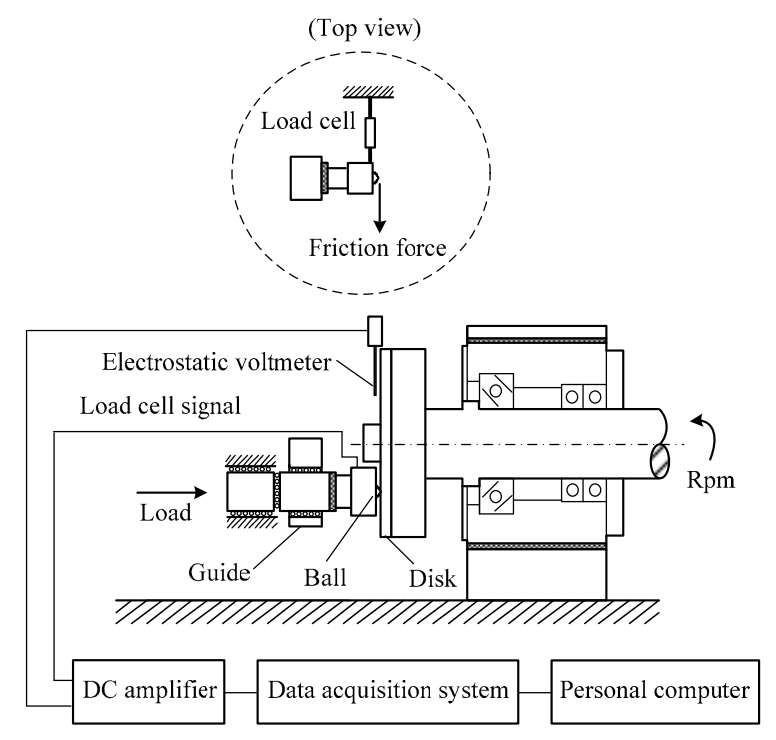

Figure 1. Schematic diagram of the ball/disk friction tester with the measuring system.

The SUJ2 steel ball is used as the Pin, and the five aluminum alloys are alternately used as the Disk, in the order of 1050, 5052, 5083, 6061 and 7075 aluminum alloys. The contents of the five disks are shown in Table 1. The size and geometry of the test specimens are shown in Figure 2. The sliding distance is set to $100 \mathrm{~m}$, the load is set to $30 \mathrm{~N}$ and $60 \mathrm{~N}$, respectively, and the sliding speed is $200 \mathrm{~mm} / \mathrm{s}$ in this study. The response time of this measurement system is less than $1 \mathrm{~ms}$ and the accuracy is $0.1 \%$ 
of the full scale. The experiments were carried out under dry friction conditions. Room temperature was maintained at $25 \pm 2{ }^{\circ} \mathrm{C}$, and relative humidity was maintained at $70 \pm 5 \%$.

Table 1. Determination of the content of the five disks (wt \%).

\begin{tabular}{cccccc}
\hline Aluminum Alloys & $\mathbf{S i}$ & $\mathbf{F e}$ & $\mathbf{C u}$ & $\mathbf{M n}$ & $\mathbf{M g}$ \\
\hline 1050 & 0.09 & 0.23 & 0.01 & 0.01 & 0.03 \\
5052 & 0.09 & 0.26 & 0.02 & 0.05 & 2.50 \\
5083 & 0.27 & 0.38 & 0.09 & 0.59 & 4.70 \\
6061 & 0.58 & 0.62 & 0.26 & 0.06 & 1.07 \\
7075 & 0.60 & 0.20 & 0.16 & 0.07 & 1.00 \\
\hline
\end{tabular}

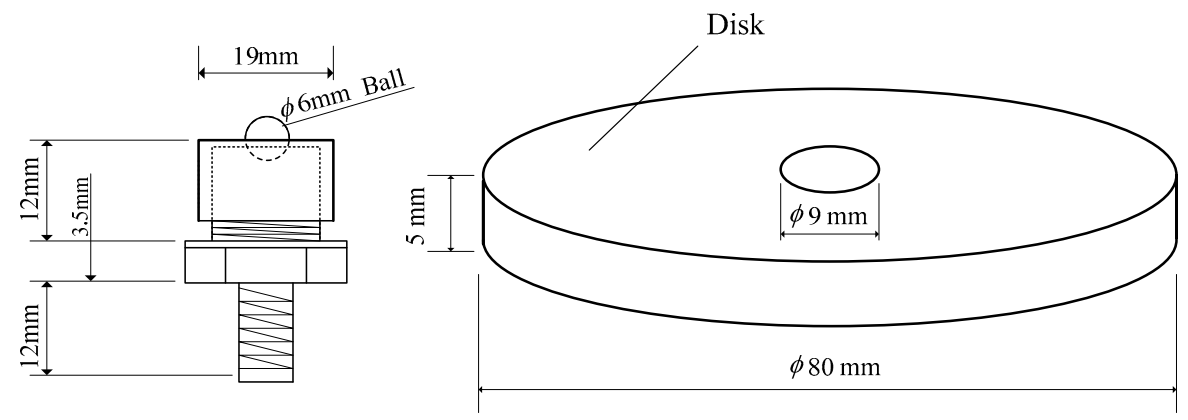

Figure 2. Size and shape of the specimens.

\section{Results and Discussion}

\subsection{Friction Coefficient}

Three reproducibility experiments were conducted. The typical results are shown in Figures 3-7. Figure 3 shows that the average friction coefficient of 1050 is 1.1. Generally, the friction coefficient changes in the range of 1.0 to 1.2, the amplitude is large, and the friction frequency is high. Occasionally, during the experimental process, the friction coefficient suddenly decreases to 0 , which may indicate the jitter between the interfaces resulting from the wear particles. The oxidation film has broken into small particles between the contact interfaces, and consequently there are some variations between the frictional interfaces. The vibration amplitude of the machine is larger during the experimental process.

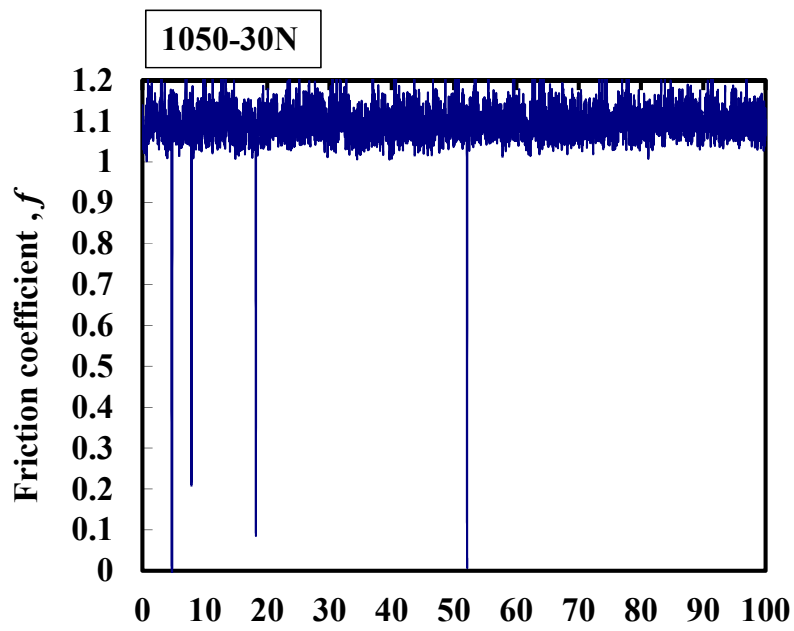

Sliding distance $(\mathrm{m})$

Figure 3. Typical response of the friction coefficient of 1050 alloy at $30 \mathrm{~N}$. 
Figure 4 shows that the average friction coefficient of 5052 aluminum alloy is about 0.85 . At the beginning of the friction process, the friction coefficient increases from 0.15 , and the maximum friction coefficient appears at a sliding distance of $80 \mathrm{~m}$. The large amplitude of the friction coefficient means that the friction is very severe, and because of the sharp change in the friction coefficient, it matches the large vibration amplitude of the machine during the experiment.

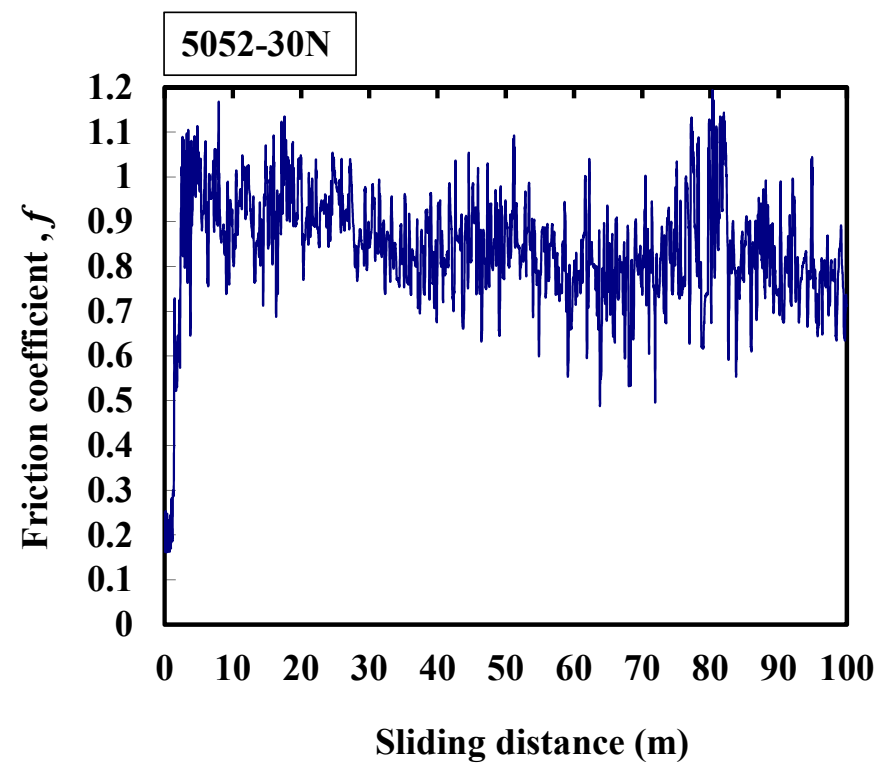

Figure 4. Typical response of the friction coefficient of 5052 alloy at $30 \mathrm{~N}$.

The average friction coefficient of 5083 is about 0.73 as shown in Figure 5 . At the beginning of the friction process, the friction coefficient increases from 0.9 to 1.2. The friction coefficient swings at around 0.7 after the sliding distance of $5 \mathrm{~m}$. Moreover, it shows a large amplitude and high friction frequency which indicate that the oxidation film has broken into small particles between the contact interfaces. As a result, the vibration amplitude of the machine is larger during the experimental process.

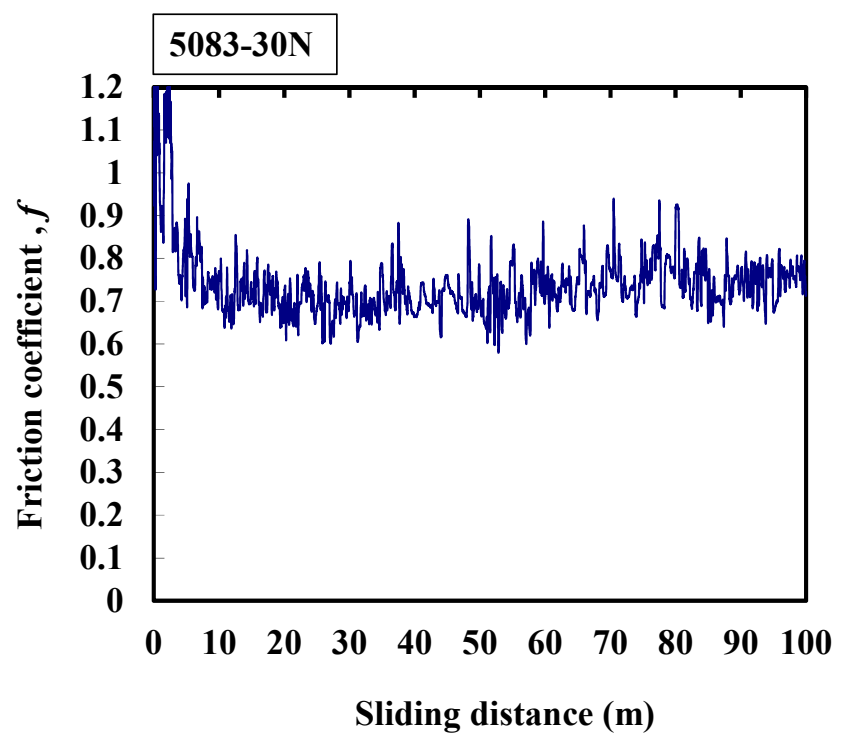

Figure 5. Typical response of the friction coefficient of 5083 alloy at $30 \mathrm{~N}$. 
The friction coefficient shown in Figure 6 is between that in Figures 4 and 5; it is representative of a few exceptions in the series. It shows that the average friction coefficient of 6061 aluminum alloy is about 0.9, the amplitude is large and the friction frequency is high. During the experimental process, the friction coefficient value changes very drastically. This may indicate the jitter between the interfaces resulting from the wear particles. Moreover, the temperature rises during the friction process [24,25], and the material is therefore softened, resulting in adhesion; and the softened surface is ploughed, generating a large and long slip tongue.

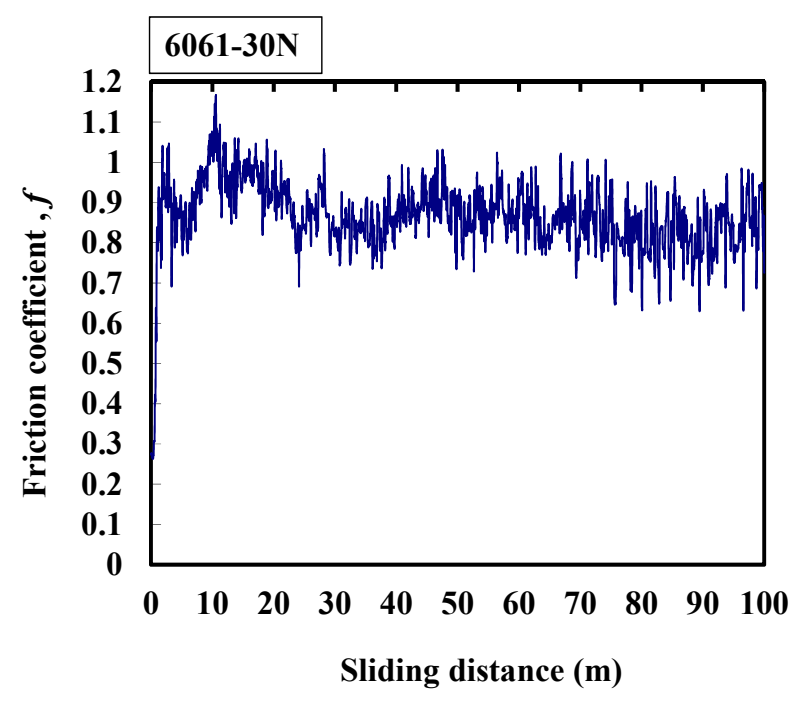

Figure 6. Typical response of the friction coefficient of 6061 alloy at $30 \mathrm{~N}$.

The average friction coefficient of 7075 aluminum alloy is about 0.7 as shown in Figure 7. At the beginning of the friction process, the friction coefficient increases from 0.5 , and the maximum of friction coefficient appears at a sliding distance of $38 \mathrm{~m}$. This may indicate that the temperature rises during the friction process, the material is therefore softened, resulting in adhesion, and low frequency wear arises; and the softened surface is ploughed, generating a large and long slip tongue. As a result, the response frequency of the friction coefficient is low. On the other hand, the friction coefficient slightly increases with the sliding distance until the experiment ends.

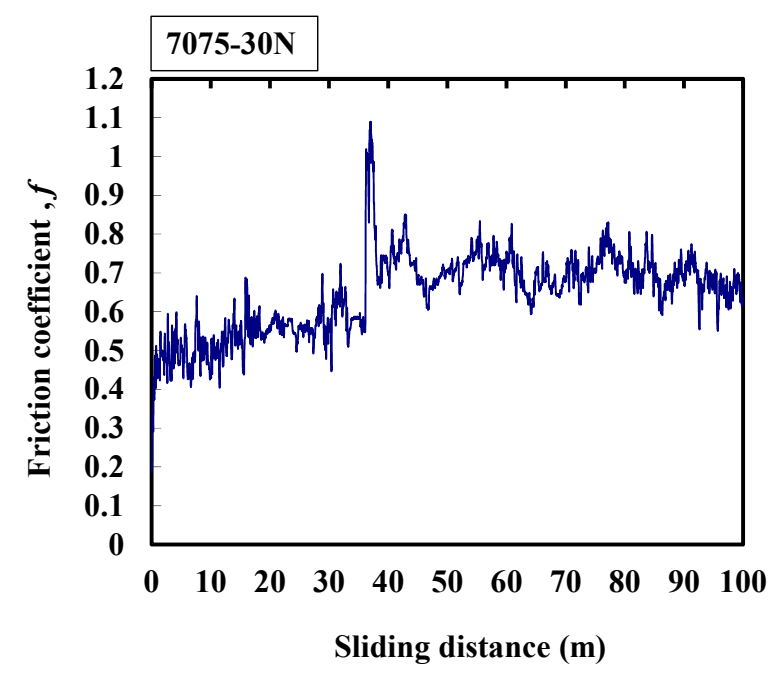

Figure 7. Typical response of the friction coefficient of 7075 alloy at $30 \mathrm{~N}$. 
According to the above results of the friction coefficient and the data in Table 1, it is shown that as the $\mathrm{Si}$ content gradually increases, the friction coefficient of the material with a higher percentage of Si decreases.

\subsection{Wear Loss}

Three reproducibility experiments were conducted. The results of the average wear loss are shown in Figure 8. As shown in Figure 8a of $30 \mathrm{~N}$, the average wear loss of 1050 aluminum alloy is $37 \mathrm{mg}$; $51 \mathrm{mg}$ for 5052 aluminum alloy; $38 \mathrm{mg}$ for 5083 aluminum alloy; $60 \mathrm{mg}$ for 6061 aluminum alloy; and $38 \mathrm{mg}$ for 7075 aluminum alloy. In Figure $8 \mathrm{~b}$ of $60 \mathrm{~N}$, the average wear loss of 1050 aluminum alloy is $44 \mathrm{mg}$, $78 \mathrm{mg}$ for 5052 aluminum alloy; $57 \mathrm{mg}$ for 5083 aluminum alloy; $153 \mathrm{mg}$ for 6061 aluminum alloy; and $58 \mathrm{mg}$ for 7075 aluminum alloy. Hence, the average wear losses are proportional to the normal loads. This indicates that the wear modes are regular. Moreover, the average wear loss of 6061 aluminum alloy is especially larger. Compared to the data in Table 1, the higher the contents of iron and copper, the more materials are removed, representing better machinability. Since the $\mathrm{Fe} / \mathrm{Fe}$ and $\mathrm{Cu} / \mathrm{Fe}$ pairs are compatible, this indicates that the wear losses for the compatible doping elements are larger [18]. On the other hand, it is worth noting that the wear loss of 5083 is quite small. This indicates that a higher content of $\mathrm{Mn}$ or $\mathrm{Mg}$ is harmless to the wear loss. Namely, if the pairs are incompatible, the wear losses are smaller [18]. As aluminum alloys are relatively soft and have a lower melting point, the wear particles produced in the friction process easily deviate from the contact interfaces, and the high temperature due to frictional heat results in material transfer. Therefore, optical microscopy of the wear track and SEM observation of the wear particle are both required for observing the wear mechanisms.
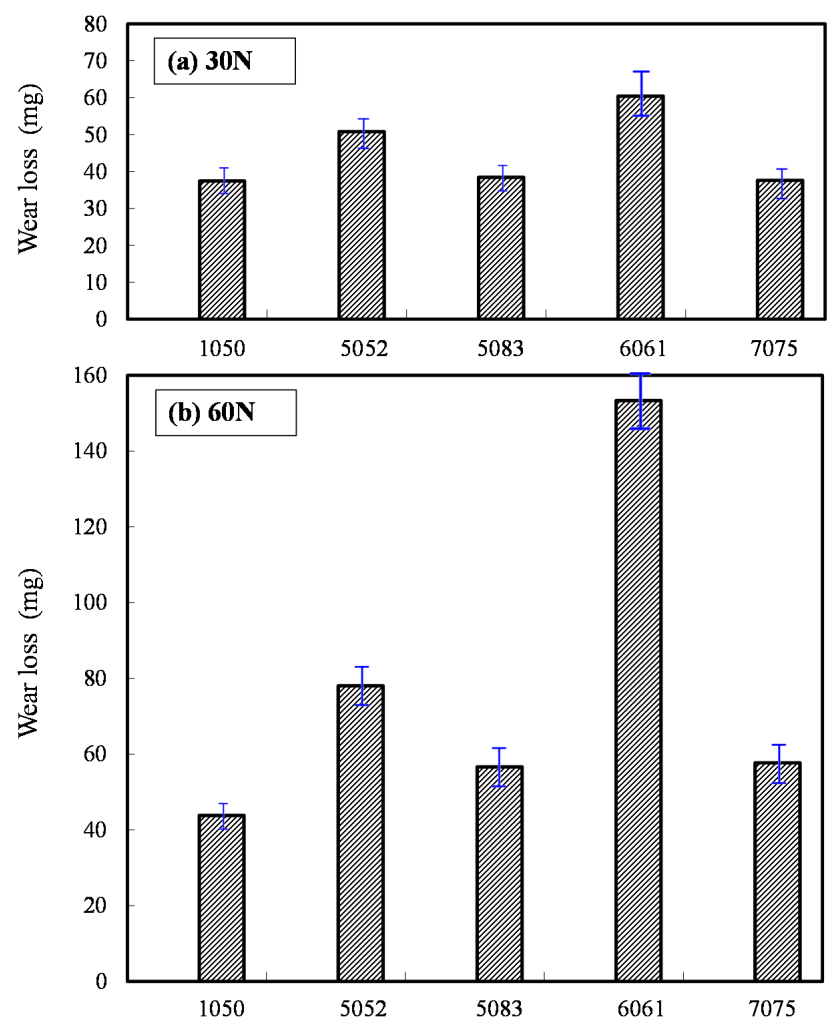

Figure 8. Average wear loss of the five alloys: (a) $30 \mathrm{~N}$; (b) $60 \mathrm{~N}$.

\subsection{Optical Microscopy of the Wear Track}

Figure 9 shows that the wear surface of the 1050 aluminum alloy presents rough wavy scratching at different widths, meaning that the vibration is relatively violent for the SUJ2 ball sliding against 
this material, i.e., there is significant material transfer and deformation during the friction process. As a result, many materials are extruded and adhere to areas outside the wear marks. This can be used to demonstrate that while the material is soft, the wear loss is not the largest.

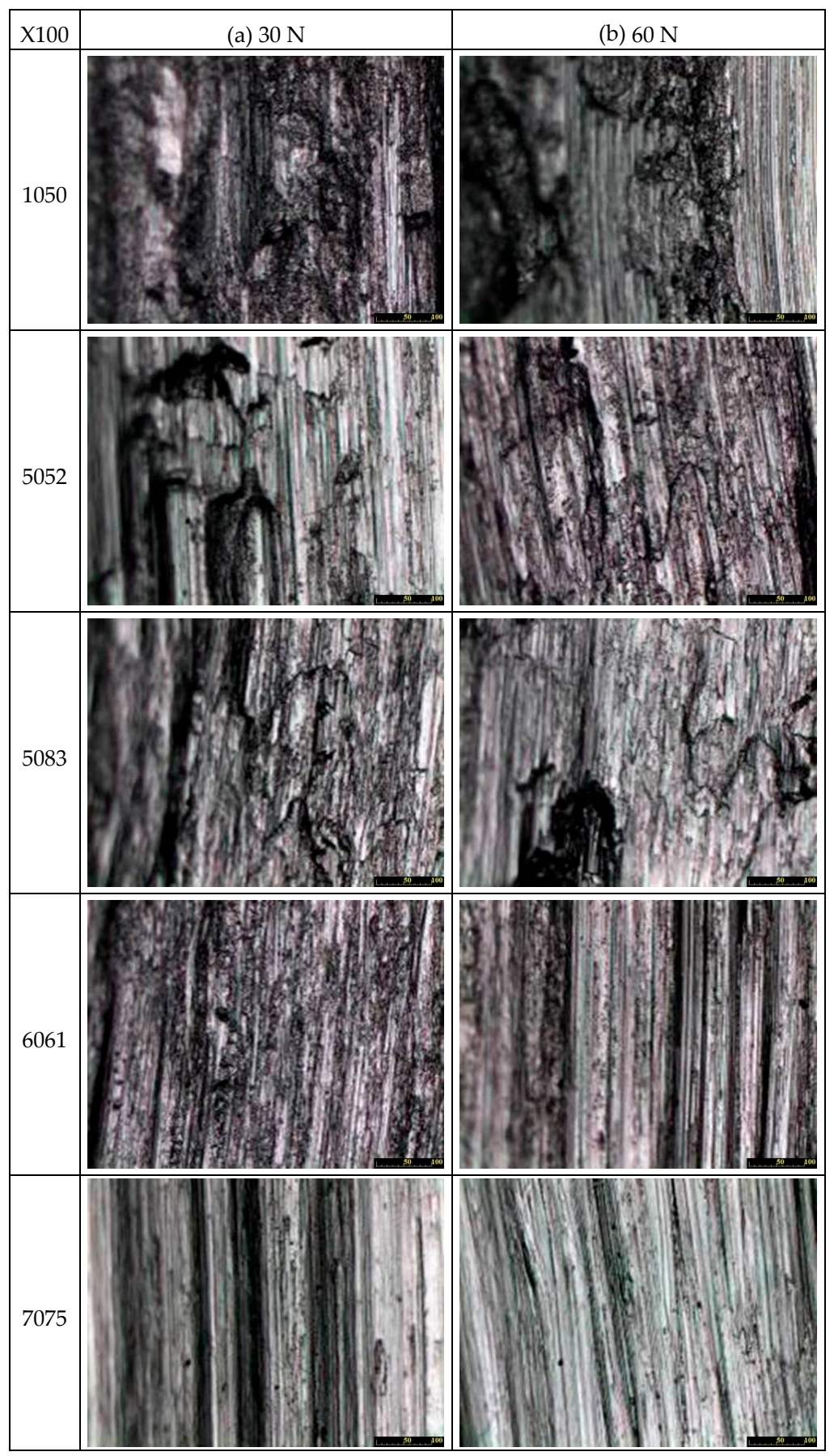

Figure 9. Optical microscopy of the wear track of the five alloys: (a) $30 \mathrm{~N}$; (b) $60 \mathrm{~N}$.

The wear scratching of 5052 aluminum alloy is similar to the case of 1050 aluminum alloy, the surfaces of which present rough and wavy scratching in different widths, the vibration is slightly violent and there is some material transfer and deformation during the friction process. Thus, part of the materials that are extruded adhere to areas outside the wear marks. Moreover, it is believed that high temperatures result in material transfer and deformation during the friction process of 1050 and 5052 aluminum alloys, and the friction scratching presents many crash and melting patterns. 
For 5083 aluminum alloy, the friction marks are narrower but deeper than for 1050 or 5083 aluminum alloys. This means that the wear mechanism of 5083 aluminum alloy is quite different from that of 1050 or 5083 aluminum alloys.

The wear surface of 6061 aluminum alloy is wide but with smooth friction tracks. Since the 7075 alloy sample has the highest hardness, it is to be expected that the scratched wear surface is the smoothest and the friction tracks are the narrowest. Moreover, the scratched wear surfaces of 6061 and 7075 aluminum alloys look quite smooth. These results match the previous results of wear loss.

\subsection{SEM Observation of Wear Particle}

Figure 10 shows that the wear particles of 1050 and 5052 aluminum alloys are flake-like and laminated; it can be reasonable explained by the fact that these materials are relatively soft and have a lower melting point, thus resulting in deformation and material transfer due to high temperature during the friction process. A large number of wear particles of large size can be found. The large wear particles are caused by the junction growth during the adhesive wear. Therefore, in these experiments, the friction coefficient is larger than the other cases due to the action of the junction growth [29].

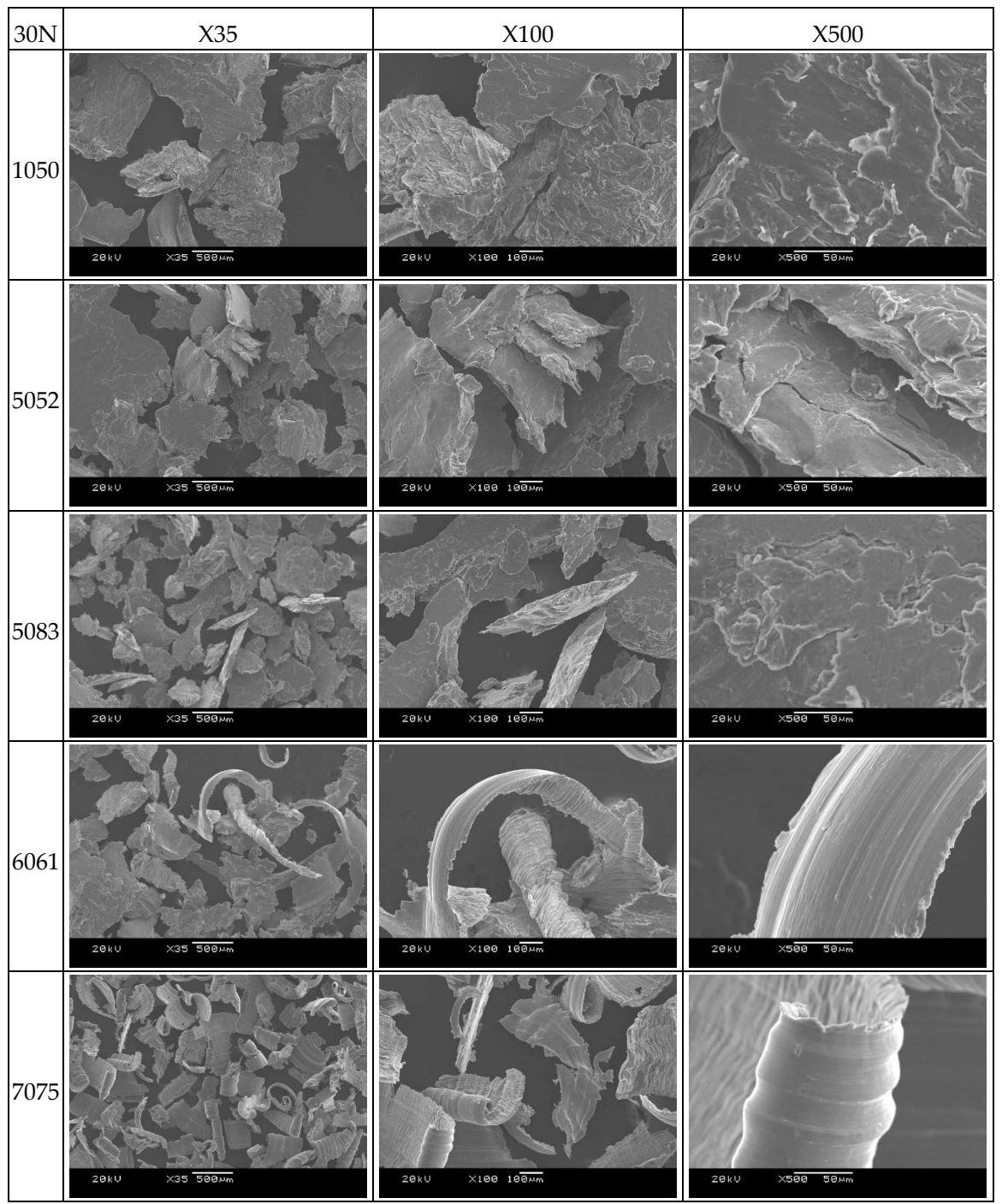

Figure 10. SEM of wear particle of the five alloys.

Most of the wear particles of 5083 aluminum alloy materials are similar to those of 1050 and 5052 aluminum alloy materials. Moreover, it is worth noting that some thick ridge-like particles are 
observed and the fracture mechanism of the wedge can be revealed. The wedge growth by plowing is quite significant. It is believed that the thick ridge-like particles result from the adhesive transfer of the wedge [30].

The 6061 and 7075 aluminum alloy materials produce strip-shaped wear particles. Several examples of ploughed particles are shown. In these two cases, ploughing is comparatively significant and large. It is believed that the ploughing wear particles are caused by grooving wear during the wear test [31].

\subsection{Frictional Models and Wear Mechanisms}

By considering all of the above experimental results as well as the previous studies by the authors [29-31], three frictional models and wear mechanisms that describe the effects of the content of doping elements on the friction and wear of SUJ2 steel sliding against aluminum alloys are proposed. It is observed from Figure 11a that the flake-like particles resulted from the higher adhesion at the junction growth region for the low content of silicon (only 0.09\%): 1050 and 5052 aluminum alloys. Hence, more friction is caused. Figure $11 \mathrm{~b}$ shows that medium adhesion is present at the interfaces for the medium content of silicon ( $0.27 \%)$ : 5083 aluminum alloy. The flake-like particles with some wedge particles were developed from both the junction growth and the adhesive transfer of the wedge. Figure 11c shows that the relatively large ploughing particles were caused by the grooving wear mechanism for the high content of silicon ( 0.6\%): 6061 and 7075 aluminum alloys. Hence, less friction is caused due to the lower adhesion. These results correspond to the previous friction coefficient responses. Wear mechanisms change as the silicon content increases, from the junction growth to the wedge particles, and even to the ploughing particles.
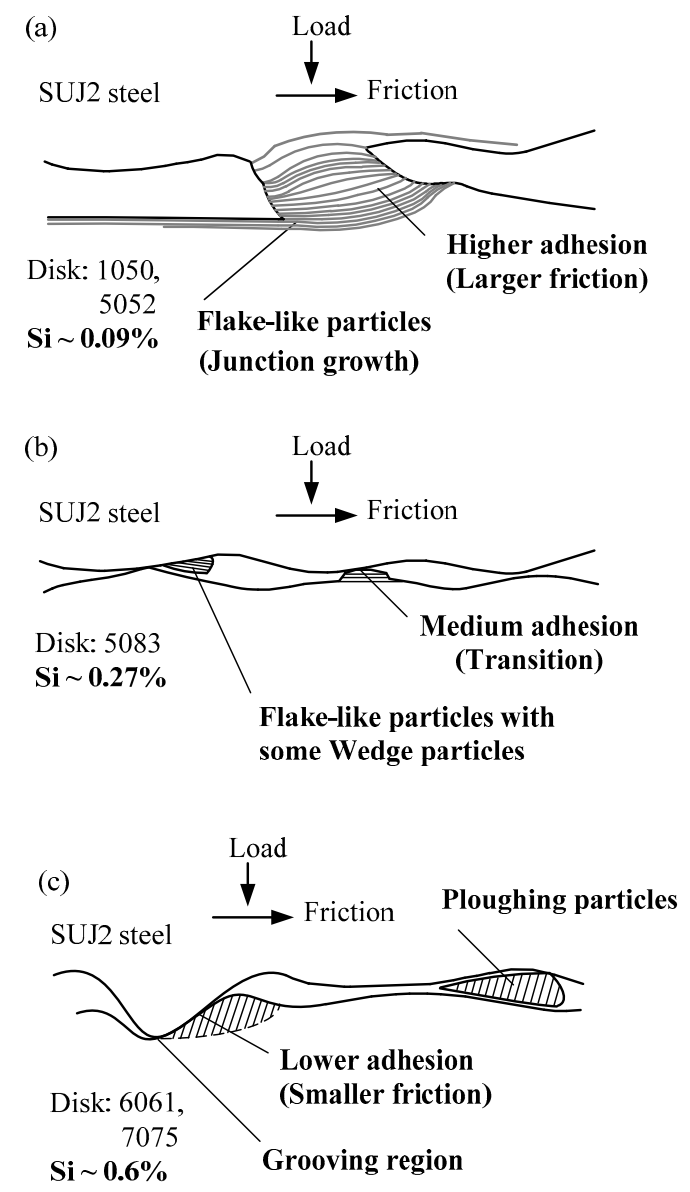

Figure 11. Frictional models and wear mechanisms of SUJ2 steel sliding against Al-Si alloys: (a) Low content of silicon: 1050 and 5052 aluminum alloys; (b) Medium content of silicon: 5083 aluminum alloy; (c) High content of silicon: 6061 and 7075 aluminum alloys. 


\section{Conclusions}

From the variations of the friction coefficient with optical microscopy and SEM observations of the wear, the following conclusions have been drawn:

1. The materials with a higher Si content percentage show lower friction. Generally, the friction coefficient decreases with increases in the Si content, and the variation of the friction coefficient is milder.

2. The 6061 aluminum alloy has severe ploughing and wear particles. The wear losses for the compatible doping elements are larger. Therefore, the higher the contents of iron and copper, the more materials are removed, representing better machinability.

3. Three frictional models and wear mechanisms that describe the effects of the content of doping elements on the friction and wear of SUJ2 steel sliding against aluminum alloys are proposed. The wear mechanisms change as the silicon content increases, from the junction growth to the wedge and the ploughing particles.

4. Based on the above three models, better choices of aluminum alloys with regards to friction and wear can be made. These results have great practical importance for the precision machinery industry.

Acknowledgments: The authors would like to express their appreciation to the National Science Council in Taiwan for their financial support under grant number MOST 105-2622-E-150-001-CC2 and MOST 105-2221-E-168-004.

Author Contributions: Yuh-Ping Chang, Zi-Wei Huang and Huann-Ming Chou conceived and designed the experiments; Zi-Wei Huang performed the experiments; Yuh-Ping Chang, Zi-Wei Huang and Huann-Ming Chou analyzed the data; Yuh-Ping Chang and Zi-Wei Huang wrote the paper; Yuh-Ping Chang revised the paper. All authors read and approved the final manuscript.

Conflicts of Interest: The authors declare no conflict of interest.

\section{References}

1. Du, J.; Wei, Z.; Chen, Z.; Li, S.; Tang, Y. Numerical investigation of pileup process in metal microdroplet deposition manufacture. Micromachines 2014, 5, 1429-1444. [CrossRef]

2. Florian, P.; Benedikt, A.; Ralf, H. Micromachining of $\mathrm{AlN}$ and $\mathrm{Al}_{2} \mathrm{O}_{3}$ using fiber laser. Micromachines 2014, 5, 1051-1060.

3. Yang, J.; Si, C.; Han, G.; Zhang, M.; Ma, L.; Zhao, Y.; Ning, J. Researching the aluminum nitride etching process for application in MEMS resonators. Micromachines 2015, 6, 281-290. [CrossRef]

4. Zhang, M.; Yang, J.; Si, C.; Han, G.; Zhao, Y.; Ning, J. Research on the piezoelectric properties of AlN thin films for MEMS applications. Micromachines 2015, 6, 1236-1248. [CrossRef]

5. Lane, J. Aluminium in Building; Ashgate Publish Ltd.: Hants, UK, 1992.

6. Krishna Kanth, V.; Pramila Bai, B.N.; Biswas, S.K. Wear mechanisms in a hypereutectic aluminum silicon alloy sliding against steel. Scr. Metall. Mater. 1990, 24, 267-271. [CrossRef]

7. Torabian, H.; Pathak, J.P.; Tiwari, S.N. Wear characteristics of Al-Si alloys. Wear 1994, 172, 49-58. [CrossRef]

8. Sarkar, A.D. Wear of aluminium-silcon. Wear 1975, 31, 331-343.

9. Prasad, B.K.; Venkateswarlu, K.; Modi, O.P.; Jha, A.K.; Das, S.; Dasgupta, R.; Yegneswaran, A.H. Sliding wear behavior of some Al-Si alloys: Role of shape and size of Si particles and test conditions. Metall. Mater. Trans. A 1998, 29, 2747-2752. [CrossRef]

10. Smith, W.F. Structure and Properties of Engineering Alloys, 2nd ed.; McGraw-Hill: New York, NY, USA, 1993.

11. Saeid, F.; Saeid, M. Effect of material structure machining characteristics of hypereutectic Al-Si alloy. Mech. Adv. Manuf. Technol. 2007, 4-15.

12. Birol, Y. Cooling slope casting and thixoforming of hypereutectic A390 alloy. J. Mater. Process. Technol. 2008, 207, 200-203. [CrossRef]

13. Rios, P.R.; Fonseca, G.S. Grain boundary pinning by Al6Mn precipitates in an Al-1wt \% Mn alloy. Scr. Mater. 2004, 50, 71-75. [CrossRef]

14. Reddy, A.S.; Bai, B.N.P.; Murthy, K.S.S.; Biswas, S.K. Wear and seizure of binary Al-Si alloys. Wear 1994, 171, 115-127. [CrossRef] 
15. Reddy, A.S.; Bai, B.N.P.; Murthy, K.S.S.; Biswas, S.K. Mechanism of seizure of aluminium-silicon alloys dry sliding against Steel. Wear 1995, 181-183, 658-667. [CrossRef]

16. Wert, J.A. Microstructures of friction stir weld joints between an aluminum-base metal matrix composite and a monolithic aluminum alloy. Scr. Mater. 2003, 49, 607-612. [CrossRef]

17. Yamauch, S.; Shibue, K.; Okubo, Y.; Sano, H.; Inumalu, S. Development of wear-resistant P/M aluminum alloys "PA4XX". Bull. Jpn. Inst. Met. 1988, 27, 492-494. [CrossRef]

18. Rabinowicz, E. Friction and Wear of Materials, 2nd ed.; Wiley-Interscience: New York, NY, USA, 1995; pp. 38-39, 84-88.

19. Alpas, A.T.; Zhang, J. Wear rate transitions in cast aluminum-silicon alloys reinforced with $\mathrm{SiC}$ particles. Scr. Metall. Mater. 1992, 26, 505-509.

20. Zhang, J.; Alpas, A.T. Delamination wear in ductile materials containing second phase particles. Mater. Sci. Eng. A 1993, 160, 25-35. [CrossRef]

21. Alpas, A.T.; Hu, H.; Zhang, J. Plastic deformation and damage accumulation below the worn surfaces. Wear 1993, 162-164, 188-195. [CrossRef]

22. Li, X.Y.; Tandon, K.N. Mechanical mixing induced by sliding wear of an Al-Si alloy against M2 steel. Wear 1999, 225-229, 640-648.

23. Subramanian, C. On mechanical mixing during dry sliding of aluminium- $12.3 \mathrm{wt} \%$ silicon alloy against copper. Wear 1993, 161, 53-60.

24. Wang, Y.; Li, X.D.; Feng, Z.C. The relationship between the product of load and sliding speed with friction temperature and sliding wear of a 52100 steel. Scr. Metall. Mater. 1995, 33, 1163-1168. [CrossRef]

25. Wang, Y.; Yan, M.; Li, X.D.; Lei, T. Frictional temperature field and wear behavior of steel 52100 with different microstructures. J. Tribol. 1994, 116, 255-259. [CrossRef]

26. Moghadam, A.D.; Omrani, E.; Menezes, P.L.; Rohatgi, P.K. Mechanical and tribological properties of self-lubricating metal matrix nanocomposites reinforced by carbon nanotubes (CNTs) and grapheme-A review. Compos. Part B Eng. 2015, 77, 402-420. [CrossRef]

27. Moghadam, A.D.; Schultz, B.F.; Ferguson, J.B.; Omrani, E.; Rohatgi, P.K.; Gupta, N. Functional metal matrix composites: Self-lubricating, self-healing, and nanocomposites-An Outlook. JOM 2014, 66, 872-881. [CrossRef]

28. Omrani, E.; Moghadam, A.D.; Algazzar, M.; Menezes, P.L.; Rohatgi, P.K. Effect of graphite particles on improving tribological properties Al-16Si-5Ni-5Graphite self-lubricating composite under fully flooded and starved lubrication conditions for transportation applications. Int. J. Adv. Manuf. Technol. 2016, 87, 929-939. [CrossRef]

29. Chiou, Y.C.; Chang, Y.P.; Lee, R.T. Tribo-electrification mechanism for self-mated metals in dry severe wear process, part II: Pure soft metals. Wear 2003, 254, 616-624. [CrossRef]

30. Chang, Y.P.; Yur, J.P.; Chou, H.M.; Chu, H.M. Tribo-electrification mechanisms for self-mated carbon steels in dry severe wear process. Wear 2006, 260, 1209-1216. [CrossRef]

31. Chang, Y.P.; Chu, H.M.; Chou, H.M. Effects of mechanical properties on the tribo-electrification mechanisms of iron rubbing with carbon steels. Wear 2007, 262, 112-120. [CrossRef]

(C) 2017 by the authors. Licensee MDPI, Basel, Switzerland. This article is an open access article distributed under the terms and conditions of the Creative Commons Attribution (CC BY) license (http:/ / creativecommons.org/licenses/by/4.0/). 